\title{
APRESENTAÇÃO
}

\section{"Sabe lá, o que é não ter e ter que ter para dar": ser profissional de História durante uma pandemia}

"Nobody Knows, What It's Like When You Don't Have and You Must Have to Give": To Be a History Professional During a Pandemic

Itamar Freitas de Oliveira ${ }^{\star}$ Margarida Maria Dias de Oliveira**

Quando Renilson Rosa Ribeiro, editor da Revista História Hoje, da Associação Nacional de História (Anpuh-BR), nos contactou no final de dezembro de 2020 com o convite para que organizássemos este dossiê que hoje apresentamos ao público leitor, lembramos do poema em forma de música que Djavan canta lindamente e do qual retiramos a primeira frase que intitula esta apresentação.

Ela pode parecer, à primeira vista, pessimista, mas não tinha esse único significado para nós. Sem sombra de dúvidas, como todos os cidadãos brasileiros estamos esgotados. Vivemos uma crise sanitária sem precedentes em nosso país, uma crise institucional, somada a crises econômica e política. Mas ela traduzia para nós, também, o desafio de responder ao convite que nos instiga a estudar a resistência de uma categoria de trabalhadores - os docentes - e de campo de pesquisa - o ensino de História.

Foi assim que enfrentamos a tarefa de discutir com a editoria da Revista as várias possibilidades de organização que se apresentavam sem tirar de vista

\footnotetext{
* Universidade Federal de Sergipe (UFS), Aracajú, SE, Brasil. itamarfo@gmail.com

** Universidade Federal do Rio Grande do Norte (UFRN), Natal, RN, Brasil. margarida_m_ dias@hotmail.com
} 
os desafios que se vislumbravam e, infelizmente, continuam para os docentes. Os problemas já existentes nas aulas presenciais que nos acompanharam no ensino remoto, como por exemplo, o fato de as salas de aulas continuarem centradas nos docentes, na oralidade e no conteúdo factual.

Essas marcas, que, pela força da tradição, insistem em caracterizar a maioria das salas de aulas brasileiras, seja na educação básica, seja nos cursos universitários de História, apontadas por nós mesmos e por outros pesquisadores, são objeto de crítica em qualquer evento que reúna profissionais de História. Contudo, seja pelas condições de trabalho, deficiências nos cursos de graduação, seja por equívocas demandas da comunidade escolar, mantemo-nos nesse círculo vicioso que detém - majoritariamente - o ensino-aprendizagem de História identificado a um passado morto e sem significado para nossas vivências.

Havia ainda problemas novos que se explicitaram com a pandemia, isto é, que estavam escondidos ou invisíveis para as instituições escolares. Mais uma vez, nos referimos tanto às instituições da educação básica quanto às faculdades e universidades. $\mathrm{O}$ acesso à internet como direito de cidadania, as exclusões extremas que inviabilizam necessidades básicas para o exercício do direito ao estudo, como alimentação, transporte, fardamento, livros, levando-nos à sensação de período de guerra, adicionado pelo fato de, efetivamente, estarmos em guerra contra um inimigo invisível e poderoso.

Não menos importante, a experiência da pandemia tornou evidente o fato de que as instituições escolares servem aos nossos públicos de estudantes como espaços de convivência e sociabilidades. São relações altamente necessárias para nossa saúde física e mental, mas, para muitos, são uma forma de encontrar os seus iguais, socializar sentimentos, problemas vivenciados no ambiente familiar que nem sempre acolhe as expressões de diversidades de pensamento, atitudes, sexualidades e tantas outras formas de agir, pensar e sentir.

Os problemas antigos foram mantidos com nova roupagem e influenciam diretamente o ensino-aprendizagem de História. Dentre os mais evidentes estão a falta de autonomia dos estudantes e as dificuldades que isso potencializa em um momento em que o professor é empregado como um orientador de tarefas e atividades discentes a serem desenvolvidas em meio à incapacidade de o estudante administrar o seu próprio tempo, à ausência de espaços/equipamentos adequados para estudo, à impossibilidade de articulação dos estudos com a sociedade de modo a tornar o aprendizado significativo para si próprio. 
Os docentes externaram essas dificuldades das mais variadas formas. Nós, como parte da comunidade formadora de professores, temos ouvido de muitos colegas da educação básica e dos nossos alunos de graduação a afirmação simples e sedutora de que "tudo seria culpa do ensino remoto".

Como, então, atender a este convite adicionando, a tudo isso que vivíamos e vivemos, o incitamento para constituir uma equipe e nos debruçarmos sobre uma das mais referenciadas Revistas do nosso campo, instituída pela mais importante entidade que congrega profissionais de História no Brasil?

Orientou-nos, então, o que consideramos deveres do ofício dos profissionais de História, todos inclusos na nossa função primordial de leitura do tempo. Era preciso - e continua sendo - fazer análise da conjuntura para que perspectivemos as tendências de permanências e mudanças e possamos agir como docentes, pesquisadores e sujeitos históricos; agir como testemunhas das forças sociais e fatos que experimentamos; refletir sobre os vestígios que deixaremos, atuando como profissionais de História para garantir o direito de memória.

Como docentes, não podemos nos eximir de orientar as gerações futuras por meio das instituições escolares e compreender o ato educativo como construtor de equilíbrios. É por meio do acesso à informação e da leitura das sociedades que podemos perspectivar entendimentos e alternativas e construir estratégias para ensinar a ler o tempo, as outras sociedades e a nossa, considerando pluralidades espaço-temporais.

Por isso, encaramos e entendemos a organização deste dossiê e o trabalho executado em equipe como construção de alternativas coletivas - mesmo estando isolados. Estudar o percurso da Revista História Hoje, revisitar as suas seções, debater com os autores, ler os depoimentos de colegas que estiveram à frente da editoria e da organização de dossiês é plantar sementes de formas diferenciadas de entender, interpretar, analisar o campo do ensino de História, é escrever História e fazer História. Por isso, agradecemos à editoria da Revista, à Anpuh-BR, aos autores e a todos que colaboraram.

Os artigos escritos para este dossiê estão sequenciados em uma perspectiva cronológica acompanhando o período de edição da Revista História Hoje, embora eles não tenham a proposta de escrever a história da Revista. São análises cujos focos foram determinados por seus autores. $\mathrm{O}$ acordo que fizemos pautava somente a indicação de, se possível, levar em consideração o contexto histórico da produção dos números em análise e observar as temáticas que 
mobilizavam a Anpuh-BR em cada momento, como entidade responsável pelo periódico.

O primeiro texto é de autoria de Itamar Freitas de Oliveira e Margarida Dias de Oliveira, que propuseram comparações da Revista História Hoje com outros periódicos científicos no período entre 2003 e 2021, além de questionarem as razões e os resultados das ações da Anpuh-BR na constituição da RHHJ e suas contribuições para o campo do ensino de História.

Em seguida, há o artigo escrito por Claudia Ricci, que se propôs a analisar os três primeiros números da RHHJ, publicados em 2012 e 2013. A autora recorreu a entrevistas, análises de documentos fornecidos tanto pelos entrevistados quanto pela entidade para situar o momento de reformulação editorial do periódico que a transforma em uma Revista totalmente voltada à temática do ensino de História. Recorrendo a essas fontes, Claudia Sapag Ricci demonstra quanto há para se compreender do complexo quadro de composição do que chamamos campo do ensino de História e suas relações com a Anpuh-BR. Os dados apresentados sobre temáticas abordadas e o perfil dos/as autores/as (gênero, área de conhecimento, nível de ensino, vinculação profissional) dos números analisados da RHHJ acrescentam questões aos pesquisadores do ensino de História, aos professores e, também, às direções da entidade.

$\mathrm{O}$ artigo que se segue foi escrito por Wesley Garcia Ribeiro Silva e tem por objetivo analisar as contribuições temáticas e de reflexões realizadas a partir das empreitadas coletivas que significam cada dossiê do periódico. Para isso, o autor levantou dados sobre autores e buscou relacioná-los às discussões que perpassavam o Grupo de Trabalho de Ensino de História e Educação da Anpuh-BR, ressaltando que esse período marca a afirmação e consolidação da Revista na área do ensino, que se demonstra, sobretudo, com a preocupação com os parâmetros avaliativos postos pelas agências de fomento e os debates curriculares e sobre a formação de professores.

Em seguida, é Carmem Zeli de Vargas Gil que colabora com esta edição especial, analisando os volumes publicados entre 2015 e 2017. A escolha da autora foi por refletir sobre a abordagem da sala de aula nas publicações do periódico. A partir dos dados analisados, ressalta-se a importância da sala de aula nas pesquisas sobre ensino de História, o que aponta para a necessidade de os pesquisadores do campo proporem debates e elaborarem definições sobre os problemas, abordagens e outros aspectos que constituem os objetos de 
análise do coletivo que se define como dedicado a esta área de pesquisa. Carmem Gil ainda realizou, em diálogo com a equipe coordenada por Oldimar Cardoso e a partir dos dados sistematizados sobre as palavras diretamente relacionadas a sala de aula nos artigos da Revista História Hoje, inferências passíveis de reflexões. Para além das análises que ainda podem ser realizadas, esse exercício foi muito importante para o trabalho de equipe que se constituiu para a execução deste dossiê.

Tiago Alinor Hoissa Benfica escreve o artigo seguinte, que analisa os volumes da Revista História Hoje, entre os anos de 2017 a 2019. O autor optou por examinar a relação texto-contexto do campo político e a área do ensino de História. Para executar seu objetivo, procurou identificar nos textos o que considerou "temas sensíveis". Tiago Benfica dedicou-se a reconstituir os principais debates com o contexto histórico e provoca a todos nós, apontando as fragilidades do campo que persistem em relação, sobretudo, ao período ditatorial (1964-1985) no Brasil.

Oldimar Pontes Cardoso, Marco Aurélio da Costa, Gustavo Ítalo Freire Martins, Waleska Maria Lopes Farias e João Carlos de Melo Silva, são os autores do artigo que finaliza este dossiê cujo objetivo é demonstrar, por meio de uma amostra - a comparação do corpus completo da Revista História Hoje com o corpus da Revista Brasileira de História -, as potencialidades e as formas de fazer o que os autores denominam de ciência aberta para historiadores. Instigam-nos a refletir sobre os dados que explicitam e nos convidam a produzir novos estudos por meio dos dados que estão totalmente acessíveis.

Nenhuma palavra será suficiente para expressar nossos agradecimentos à confiança depositada em nós para efetivarmos a tarefa de organização deste dossiê e para dizer o quanto foi prazeroso e educativo trabalhar com esta equipe. Esperamos que os leitores e as leitoras nos agraciem com suas críticas, sugestões, apropriações.

Boa leitura! 